\title{
CORRIGENDUM
}

\section{Site promiscuity of coliphage HK022 integrase as tool for gene therapy}

M Kolot, N Malchin, A Elias, N Gritsenko and E Yagil

Gene Therapy (2015) 22, 602; doi:10.1038/gt.2015.37

Correction to: Gene Therapy (2015) 22, 521-527; doi:10.1038/ gt.2015.9; published online 12 March 2015

Since the publication of this article, the authors have noticed an error in the text. In the Discussion section, the last line of the third paragraph should say 'This shorter palindrome exists also in the core of the wild-type attP (Figure 3a) and only in attP of $\lambda^{\prime}$.
The author names were also published incorrectly in the online PDF. The correct author names are listed above.

The html and online versions have been amended. The authors apologise for any inconvenience caused. 